\title{
The melodic dictation in the traditions of Russian music education
}

\section{Dzhumanova, Lola ${ }^{a}$}

${ }^{a}$ Moscow P.I. Tchaikovsky Conservatory, Department of theory music, Central Music School (college), Russia.

\begin{abstract}
In Russia solfeggio became an academic subject at the time of foundation of Saint-Petersburg and Moscow conservatories. Coming from Western Europe, in Russia solfeggio gained its own traditions of teaching. There were established three main activities - vocal and intonation exercises, hearing analysis and dictation. They were defined by the scientist of the XXth century - professor of Moscow Conservatory I.V. Sposobin.

It is a melodic dictation that became a comprehensive model for the development of prospect musicians' skills. The reason is in the combination of various tasks, such as the ability to hear, realize, memorize and record a relatively complete musical part based on a certain number of replays. Over the years of evolution in the Russian teaching school the dictation obtained logical representation, enabling to teach and perceive music, tonal and atonal. The same dictation significantly differs in the Russian tradition from its French analogue.
\end{abstract}

The report describes the evolution in the three-level system of music education, comparing it to the traditions of other countries.

Keywords: solfeggio, a melodic dictation, a comprehensive task, multilevel musical thinking. 


\section{Introduction}

The melodic dictation as one of the solfeggio course activities has its national traditions in Russia. It was N.A. Rimsky-Korsakov who first spoke about the need to record music episodes from memory. His words referred to teaching solfeggio in two open conservatories: first in Saint-Petersburg, and then in Moscow. The necessity to record music episodes from memory (today it is called a melodic dictation) is primarily related to acquiring the skills of hearing, memorizing and written reproduction of the music text using notes. This skill is especially topical for those studying «free creativity» (today composition). V.Sposobin, professor of the Moscow Conservatory, defined in the 1930s three major activities of the solfeggio course: sol-fa or vocal-intonation skills, hearing analysis and dictation. While the first activity is the closest to its «source» - solfeggio, originating from Italy as exercises for singing, hearing analysis is the most professional training for musicians' hearing, combining both hearing and understanding the sound vertical (intervals, chords) and requiring the knowledge of musical theory. The least ordinary activity is the melodic dictation. What are the methodological traditions of writing a dictation in Russia?

\section{Dictation as a comprehensive activity}

While recording a melodic dictation, the writer uses hearing, memory, music material analysis, meter-and-rhythmical skills, music basics, knowledge in the theory of music. The composite format of this complex work requires thorough preparation. It is quite reasonable that dictations are written starting from the first stage of the three-level system of music education and finishing in the first year of higher education. It is to be noted that for some musicians (conductors and music historians), becoming a post-graduate student also involves an examination on Solfeggio as a dictation, since it shows the level of development of the candidate's hearing, memory, music theory and understanding.

At the same time the range of tasks for writing dictations at different stages of education considers manageable complexity of the level. It takes into account the fact that small kids do not have the skills of writing notes, so dictations for 5-7-year-old children are given orally as short (2-4 bars) melodic motifs, which should be sung/played on the instrument/clapped after listening to them once or twice. These are the so called melodic and rhythmical dictations. A melodic dictation requires of children accuracy in reproducing intonation rhythm. Here children show not only their hearing abilities, but also the quality of their music memory.

In the primary music school it is necessary to teach children perceive a dictation as a routine solfeggio class activity. This outer setting means regular memory training. Owing to 
the basis of the major/minor key in the Russian system of music education, the topical questions include the specifics of the tonal development in this dictation: which degree the dictation started with, which it finished with, what skips were there in the melody, what melodic idioms were included, what specifics were noticed in the rhythmical groove. Another feature is including the theoretical material studied in class into the dictation. All the above questions enable to train analytical approach to the melody heard.

In the middle music school, teachers normally give a monothematic dictation with the length of 8 bars, which aims to facilitate students' understanding of the simplest structure of the music period of repeating/non-repeating/unified format. The melody heard must be noted down after 6-8 replays, during which they identify the key, metric signature, melodic structure, caesuras, rhythmical and melodic specifics. It is vital to record a dictation.

The classical tradition of writing a dictation means recording it from memory, and not taking of shorthand notes following the performance. The procedure of writing a dictation emphasizes integral perception of the musical piece, including interaction of all its parts. Therefore, artificial division into smaller parts (sequences of notes, rhythmical scale, bars) may be only a temporary technique to find out and solve problems. The integrity of perception is the main difference from the procedure of writing a dictation in France, where a dictation is played in full at the beginning and the end of writing, while in the middle several bars are played 2-3 times in a row. However, the Russian system does not exclude recording the note text by parts, but only provided that the structure of the dictation is clear, and the number of bars is thus evident.

In the music college the task is to teach students write $1 / 2 / 3$-voice dictations using chromatisms for transitions and modulations to other keys. It is also important to hear the types of correlation between voices in a polyphonic dictation (direct, parallel, indirect, opposite), be knowledgeable about homophonic-harmonic and polyphonic composition, understand the principles of writing chromatic sounds. The issues of the dictation structure (analytical approach) are always topical.

A completely different dictation perception is practiced at higher educational establishments. All the technical memory and hearing training should be left behind. The aim of the conservatory dictation is to record a polyphonic dictation with a changeable number of voices taking into account genre and stylistic features of the music material. It is curious that for the first time prospect undergraduates encounter stylistic dictations and genre performance at the entrance examination, where, pianists, for example, are requested to write down the dictation in Prokofyev's or Rakhmaninov's style as a piano miniature.

Conductors and music historians record 3-voice dictations with expanded tonality and elements of polyphonic imitations. 
Naturally, the question is: what material may be used for genre and stylistic dictations. In the educational practice of the first two stages of the three-level system of music education dictations are mainly instructive, since they must «work» for solving specific theoretical difficulties and at the same time they must be structurally complete. Music pieces are often inappropriate here. At higher educational establishments the situation is the opposite: the material often includes fragments of the contemporary works. The aim is to teach and perceive a contemporary miniature, because it has a well-developed music language, using modern notation principles, and gives another horizontal and vertical горизонтали. Undoubtedly, some of the most suitable miniatures here are such pieces as those from "Microcosm" by B. Bartok. However, to achieve genre diversity it is much more interesting to use fragments from chamber and vocal, chorus or symphonic music.

\section{Dictation as a result of working on vocal-intonation and hearing skills}

A dictation could have failed as the activity if there was no two-fold preparation for solfeggio: vocal-intonation skills and hearing analysis.

Considering memory development, it is to be kept in mind that initially the child's musical memory is developed by signing song-melodies and learning them by heart. At this stage the basics of the analytical approach to a music fragment is made. How many phrases are there in the song? In the text they are usually divided by a caesura. Which of them repeat? What is the difference between them? Does the stop on the unstable degree in the middle of the song sound as complete? Where can we put a «full stop» in the musical development? Obviously, in the end, where we come to the key note. All these questions and answers are to listen and hear the music text attentively and distinctively. It is clear that the material for singing and learning by heart is becoming more and more complex at each step of development. Memory training is in place till the beginning of the higher school solfeggio.

Another important aspect of preparing to write a dictation is hearing analysis. This form of work may include various models for hearing: starting from separately played sounds in/out of a key, associative melodic idioms (auxiliary and transit idioms, leading notes, tetrachords, skips with filling etc.), intervals and chords in/out of a key, harmonic fourvoice sequences and separately played altered chords. The skills of this hearing analysis may be useful for the melodic dictation.

\section{Issues of the tonal thinking in the melodic dictation}

In Russia Kodály Method did not become widely spread, similarly to the system of the absolute «C». The typical feature of the Russian solfeggio is probably its base on the key and tonality, which is the foundation for the future model changes. This sequence makes the Russian system different, for example, from the Danish one, where J. Jersild outlines 
various tonalities via numerous options of tetrachords and their further combination. In this respect we are closer to the research done by E. and F. Galofré Mora, where they gradually build up the tonality (based on the example of $\mathrm{C}$ major), and then they build the expanded basic triad. It is also similar in terms of the principle of highlighting rhythmical component for activation. In «Solfeggio» Galofré Mora tends to the following integration of the rhythmical and melodic parts (melody and its rhythmical accompaniment).

Since dictations are written in different keys, the freedom of orientation is required. Therefore, preparation in sol-fa is not only to learn music fragments by heart and analyse their structure, but also to actively translating them into different keys. The knowledge of the quint course of parallel keys is advantageous.

The basis on the key and tonality has long been the foundation for students' hearing skills, so at the stage of the higher school solfeggio going beyond tonality or its expansion entails difficulties in writing dictations. The way out may be in the earlier introduction of the contemporary music in the examples for sol-fa. For example, it is suitable to commence the introduction with the modern interpretation of the tonality with music by S. Prokofyev, D. Shostakovich, and R. Shchedrin. It can be used at college solfeggio classes. In this case sample dictations may include «Polyphonic dictations» by N. Kachalina. Another intermediary option of working on tonality expansion is the use of instructive dictations, based on the principle of repeating a tonal phrase or a sentence by sharpening or flattening. This idea was used in the «Polyphonic dictations» by A. Myasoyedov.

\section{Innovative methods of working for the melodic dictation in higher education}

The specific feature of the melodic dictation in higher education is to go beyond the diatonic key in chromatic. Such a goal seems to be quite a new phenomenon, promoted in solfeggio for the last 30 years. Often, the approach to the tonal perception changes: socalled "tonal limited transposition" replaces the traditional major and minor keys. Knowing the Olivier Messiaen's tonal system involves their active use in practice. In the metrorhythmic part of dictation changes in melodic interval sizes, which could be unstable, comes to replace the stability bar. The rhythmic simplicity of the beat pattern alters for unusual divisions. Number of voices may change throughout the dictation, that usually due to the characteristics of the genre of musical material. A textured design of the note text, depending on the genre of dictation, becomes a natural requirement.

A dramatically increased complexity quite naturally has caused difficulties in writing dictations for students. Multipolar difficulties involve complex of preparatory work and new forms of dictations. 
The need to perceive complex musical material requires more serious forms of memory development. An innovation in the field of musical dictation became a "visual-aural dictation" (N.Kachalina), which goal was to apply visual imagery to the hearing skills development. In particular, students are suggested visually memorizing music, which can then be played on an instrument or be written in musical notation. Needless to say, this form of dictation assumes intensification of internal hearing perceptions.

Another type of activation of the hearing is the so-called "timbre dictations" (T.Litvinova), that involves the musical notation of the piece of music from polyphonic dictation performed by traditional and modern ensembles. The task of such a dictation is hearing in polyphonic texture the timbre line of one instrument.

In an effort to go beyond the diatonic, the training dictations of high artistic performance have been developed by A. Myasoedov. He uses tonal shifts on a short phrase, which can be variably shifted a semitone up or down while maintaining or changing the key. Any chromatic movement allows to fix attention on the here and now playing tonality, generating associative-aural perception of any tonality as such, without regard to the relationships with others.

It would be wrong to say that new forms of work on melodic dictation had affected only solfeggio in high school. A light version timbre exercise can be found in college and music school where interactive melodic diction is cultivating. Multimedia capabilities allow children to practice writing melodic dictation in a playful way by inserting suitable puzzlebar in the right places with missing parts.

In conclusion, it should be emphasized that the objective of the dictation is never to find drawbacks in music education, as it is frequently seen in test examinations. It is rather the ability to hear the musical material, understand it and literally reproduce it with notes. However, this task can be implemented only under the harmonious interaction between academic subjects, included into the system of music education.

\section{References}

Alexandrova, N., Maslieva, N. (2013) Timbre dictations. Novosibirsk.

Dzhumanova, L., Zhurova, E. (2014) Traditions and innovations in Music Theory Pedagogy in Russia (To the question of Interaction of East and West). Eight European Music Analysis Conference. Abstracts, p.96, EuroMAC Leuven

Galofre y Mora, E. y F. (1988) Solfeig. Llenguatge musical. Barcelona.

How to teach solfeggio in the XXI century. (2006) Moscow: Classic-XXI.

Jersild, J. (1966) Ear training. Basic instruction in melody and rhythm reading.Hansen.

Kachalina, N. (1988) Polyphonic dictations. Moscow: Muzyka. 
Myasoyedov, A. (2007) Polyphonic dictations. Moscow: Muzyka.

Litvinova, T. (2012) Timbre solfeggio. Saint-Petersburg.

Triz (1997). An Approach to systematic innovation. GOAL/QPC Research Committee. Volume 1 of Research Report, 2. 